\title{
Bone mineral density (BMD) and bone-related biochemical markers after short-term supplementation in normal and osteoporotic elders, the pilot study
}

\author{
Yuttana Sudjaroen ${ }^{1 *}$, Pimporn Thongmuang ${ }^{2}$ \\ ${ }^{1}$ Department of Applied Science, Faculty of Science and Technology, Suan Sunandha Rajabhat University, Bangkok, Thailand. \\ ${ }^{2}$ Department of Aesthetic Health Science, College of Allied Health Science, Samut Songkhram Education Center, Suan Sunandha Rajabhat University, Samut \\ Songkhram, Thailand.
}

\begin{tabular}{l}
\hline ARTICLE INFO \\
\hline Received on: $21 / 09 / 2018$ \\
Accepted on: 08/10/2018 \\
Available online: $30 / 12 / 2018$ \\
\\
\hline Key words: \\
Osteoporosis, bone mineral \\
density (BMD), bone turnover \\
markers (BTMs), calcium and \\
vitamin D supplement, bone- \\
related biomarkers.
\end{tabular}

related biomarkers.

\begin{abstract}
Bone mineral density (BMD) and bone-related marker measurements in elders are necessary to provide for osteoporosis diagnosis and can be predicted supplement effectiveness. This study was aimed to evaluate and compare the effectiveness of short-term calcium and vitamin D supplements in normal and osteoporotic elders. The crosssectional study was determined for BMD; bone turnover markers, including procollagen type $1 \mathrm{~N}$-terminal propeptide (P1NP), osteocalcin, beta-crossLaps (CTX), and alkaline phosphatase (ALP); 25-hydroxy-calciferol [25-(OH)D]; and bone-related minerals in normal group $(N=30)$ and in osteoporotic elders $(N=30)$ before and after calcium and vitamin D3 supplements daily for 3 months. BMD was measured by calcaneal quantitative ultrasound. Serum concentrations of bone-related biochemical markers were determined by automatic analyzers. Paired $t$-test was used for the statistical analysis. BMD of both groups before and after supplementation was significantly increased. In normal group, phosphorus, ALP, and P1NP were significantly increased $(p<0.05)$, and 25-(OH)D was strongly significant $(p<0.0001)$. In an osteoporotic group, magnesium and $25-(\mathrm{OH}) \mathrm{D}$ were increased at a strong level of significant $(p<0.0001)$. Moreover, the decrement of CTX after supplementation was strongly significant $(p<0.0001)$ in the osteoporotic group. The short-term supplement increased the rate of bone formation in normal group and decreased bone resorption in osteoporotic groups.
\end{abstract}

\section{INTRODUCTION}

Maintaining a calcium intake of at least $1,000-1,200$ $\mathrm{mg}$ /day has long been recommended for older individuals to treat and prevent osteoporosis. Calcium supplements are commonly taken to achieve such intakes, which are considerably higher than the average intake of calcium in the diet of older people, around 700-900 mg/day (Consensus conference, 1984; IOM, 2011; Tai, et al., 2015). Increasing calcium intake from dietary sources increased bone mineral density (BMD) by $0.6 \%-1.0 \%$ at the total

\footnotetext{
${ }^{*}$ Corresponding Author

Yuttana Sudjaroen, Department of Applied Science, Faculty of Science and Technology, Suan Sunandha Rajabhat University, Bangkok 10300, Thailand.E-mail: yuttana.su@ssru.ac.th
}

hip and total body at 1 year and by $0.7 \%-1.8 \%$ at these sites, and the lumbar spine and femoral neck at 2 years (Tai et al., 2015). In addition, evidence supports the use of calcium, or calcium in combination with vitamin D supplementation, in the preventive treatment of osteoporosis in people aged 50 years or older. For the best therapeutic effect, we recommend minimum doses of 1,200 $\mathrm{mg}$ of calcium and $800 \mathrm{IU}$ of vitamin D for combined calcium plus vitamin D supplementation (Tang et al., 2007).

Elevating of Thai population is a trend to increase with the number of osteoporosis in elders (Pongchaiyakul et al., 2003) and will be fast increase along with common chronic diseases, such as diabetes mellitus and cardiovascular diseases (Maghbooli et al., 2016a; 2016b; Sudjaroen and Thongmuang, 2018). From Thai nation-wide survey, the age-adjusted prevalence of osteoporosis in Thai women age ranges from 40 to 80 years was $13.6 \%$ and $19.8 \%$ for femoral neck and lumbar spine, respectively. 
For men, the age-adjusted prevalence of osteoporosis was $12.6 \%$, $4.6 \%$, and $3.9 \%$ at the femoral neck, lumbar spine, and both sites, respectively. The Asian Osteoporosis Study, a multi-national research survey was documented the incidence of hip fracture in Thailand, which reported age-adjusted rates (per 100,000) were 114 and 289, in men and women, respectively (Lau et al., 2001; Pongchaiyakul et al., 2003). Vitamin D insufficiencies of Thai elderly women in the urban area were higher than in rural area because of the differences in lifestyle (Soontrapa et al., 2009a; 2009b). Study on the multi-centers from five provinces of Thailand was covering all regions of Thailand except southern area which represented the calcidiol level of Thai premenopausal women was $29.09( \pm 0.42) \mathrm{ng} / \mathrm{ml}$, and with the cut point of $\leq 35$ $\mathrm{ng} / \mathrm{ml}$; the prevalence of vitamin D insufficiency was $77.81 \%$, and PTH and bone resorption markers were trended to increase (Soontrapa et al., 2009a). Hypovitaminosis D, and low level of 25-hydroxy-calciferol [25- $(\mathrm{OH}) \mathrm{D}]$ are common occurring in Thai premenopausal women; and the risk will be increase in elderly women who living in the rural area (Soontrapa et al., 2009b). The prevalence of vitamin D insufficiency among elderly males was $13.6 \%$, while the bone turnover markers [beta-crossLaps (CTX) and procollagen type $1 \mathrm{~N}$-terminal propeptide (PINP)] levels were in the normal Thai reference range (Soontrapa et al., 2015).

The numbers of elders in Sumut Songkhram province are a trend to increase and approximately $16.7 \%$ of elders are home and bed-bound elders who are difficult to assist by that medical staff and equipment. The early diagnoses of osteoporosis before fractures occur and by assessing the bone mineral density and with early treatment, osteoporosis can be prevented. Therefore, increasing awareness among doctors, which, in turn, facilitates increase awareness of the normal populace, will be effective in preventing this epidemic or community level (Sözen et al., 2017). In addition, BMD, vitamin $\mathrm{D}$, and bone-related markers measurement of elders are necessary to provide for osteoporosis diagnosis and bone turnover or bone-related biochemical status, which are able to predict the supplement effectiveness, especially in case of mass supplement in community level. Aims of our recent study were evaluated and compare the effectiveness of short-term calcium and vitamin D supplements in normal and osteoporotic elders by determining of BMD, serum vitamin D [25-OH vitamin $\mathrm{D}$ (25-(OH)D)], bone turnover markers (BTMs), and bone-related minerals before and after supplementation.

\section{MATERIALS AND METHODS}

\section{Participants and demographic data}

The cross-sectional study was carried out from November 2017 to April 2018 (this period including public relation and health service), 150 of health customers were included from academic health service program at Amphawa district, Sumut Songkhram, which was responsible by Sumut Songkhram campus, Suan Sunandha Rajabhat University. The screening of BMD was done for classified bone density status as normal, osteopenia, and osteoporotic persons.

Normal $(N=30)$ and osteoporotic female elders $(N=30)$ were sampled in this pilot study for determining BMD, 25-(OH)D, BTMs, and bone-related minerals in before and after supplements. Informed consent of all participants was done, and the study protocol was approved by the Ethical Review Committee. The inclusion criteria: (1) female elders were aged $\geq 60-75$ year old; (2) consciousness and interactive; and (3) had not severe medical conditions. The exclusion criteria: (1) elder was combined with metabolic bone disease (osteomalacia, Paget disease, or primary hyperparathyroidism); (2) had accident especially with fracture; (3) taking daily calcium and vitamin D supplements before joining in the program at least 1 year; and (4) pathological fracture (Gao et al., 2015; Slevin et al., 2014). Anthropometric data, medical history, and health behaviors (including related risks) were recorded by physical examination and interview. The elders with poor literacy and/or unable to read as well were helped for filling the form of a questionnaire.

\section{BMD and biochemical measurements}

BMD was measured by calcaneal quantitative ultrasound (QUS), ultrasound bone densitometer (SONOST-2000, OsteoSys, Korea), and the instrument protocol and data interpretations were followed with manufacturer instruction. According to BMD status, the elders were divided into osteoporotic ( $\mathrm{T}$ score at or below -2.5 ), osteopenia ( $\mathrm{T}$ score between -1.0 and -2.5 ), and normal ( $\mathrm{T}$ score at -1.0 and above) elders. Each $6 \mathrm{ml}$ of fasting blood sample was obtained by venepuncture from the median cubital vein during the morning (7-9 a.m.). Nearly $6 \mathrm{ml}$ of blood sample was drawn into clotting blood tube for centrifuged and processed within 2 hours after phlebotomy and stored at $-20^{\circ} \mathrm{C}$ (Young and Bermes, 1999). Each serum concentrations of BTMs including procollagen type $1 \mathrm{~N}$-terminal propeptide (P1NP), osteocalcin (OC), CTX, and alkaline phosphatase (ALP); 25-(OH)D; and bone-related minerals (calcium, phosphorus, and magnesium) were determined by Cobas E411, Cobas E601, and Cobas E501 automatic analyzer (Roche Diagnostics, Basel, Switzerland), respectively. The within-run and between-run CVs were $<10 \%$. Control materials and pooled serum were also done prior sample test for accuracy checking. The supplemented and control (placebo) group were selected according to BMD screening, which was defined as osteoporotic elder group ( $\mathrm{T}$ score at/or below -2.5) and control or normal group ( $\mathrm{T}$ score at -1.0 and above), respectively. BMD and biochemical data of supplemented and normal groups were measured prior recruitment of participants for supplement study and were done again after supplement study was finished.

\section{Calcium and vitamin D supplementation}

Commercial calcium and vitamin $\mathrm{D}$ tablet contain calcium $600 \mathrm{mg}$; vitamin D3 (cholecalciferol) $800 \mathrm{IU}$, and other minerals including, magnesium, zinc, copper, and manganese were $50,7.5,1$, and $1.8 \mathrm{mg}$, respectively. This commercial supplement tablet had been approved by the Thai food drug administration (Thai FDA). Each participant took one tablet daily with food and with a full glass of water, respectively, for 3 months and recommendation of intake for each participant was accorded Thai recommended dietary allowance (Thai RDA) and manufacturer indication, which was informed by senior pharmacist/nutritionist. The short term of daily supplement period was 3 months. After the study program was finished, all participants from both groups will continue intervention within another 3 months by the suggestion of medical staff and receive the tablet supplement. 


\section{Statistical analysis}

The Kolmogorov-Smirnov test was used to test the normal distribution of data. Paired $t$-test was used to compare the continuous variables as appropriate between before and after supplementation of normal and osteoporotic groups. The statistical significance was judged at $p<0.05$. SPSS 20.0 software was used for statistical analysis (SPSS, Chicago, IL).

\section{RESULTS AND DISCUSSION}

Average ages of control and osteoporotic groups were 65.4 \pm 5.4 and $65.4 \pm 9.8$ years old, respectively. Health behaviors and anthropometric data of both groups were seemed to be similar, such as daily food intake, no risk of smoking and alcoholics, and normal body mass index (data not shown). The consumption of both groups has sufficient calcium intake due to frequent intake of seafood diets, such as small fishes (able to eat with bone) and shrimp paste (high content of calcium); and vitamin D intake due to properly sunlight exposed. The other risks of osteoporosis may relate to increment of bone resorption and some chronic disease, such as diabetes mellitus, which recorded from medical history by interviewing. BMD of the control group was T-score $=-0.80 \pm 0.41$ and was within normal range, while average BMD (T-score) of osteoporotic elders was $-2.85 \pm 0.23$ and interpreted as osteoporosis. Before calcium and vitamin $\mathrm{D}$ tablet intake, mean of serum calcium, phosphorus, magnesium, ALP, 25-(OH)D, OC, P1NP, and CTX normal (control) group was within normal range (Table 1). However, the mean of serum calcium and magnesium in an osteoporotic group was lower than normal; and mean of CTX was higher than normal (Table 2). The BMD after calcium and vitamin D supplementation in both groups was significantly increased and strong significant was occurred in the osteoporotic group $(p<0.0001)$. In normal group, serum phosphorus, ALP, and P1NP of before and after supplement were significantly increased $(p<0.05)$; and 25-(OH) $\mathrm{D}$ was strongly significant $(p<0.0001)$. In the osteoporotic group, serum magnesium, $25-(\mathrm{OH}) \mathrm{D}$ of before and after supplement were increased at a strong level of significant $(p<0.0001)$ and serum calcium was slightly significant. Moreover, the decrement of CTX after supplementation was strongly significant $(p<0.0001)$ in the osteoporotic group.

According to our present study, we were representing the outcome of short-term calcium and vitamin D supplementation in normal and osteoporosis elders (post-menopausal women) during 3 months, which were indicated by BMD, vitamin D status, and bone-related biochemical markers. The age-range, dietary intake, and health behaviours between normal and osteoporosis group were similar. Age was an important determinant of risk for bone reduction. Less bone reduction in people aged 50-70 years than in those who were older than 70 years (Tang et al., 2007). In our study, similar age ranges of normal and osteoporosis ( $\sim 65$ years old) were similar responding to supplement; and a similar pattern of dietary intake and health behaviors can reduce the interference, which may affect to this comparative study.

Significant increments of BMD in both groups, which were monitored by using calcaneal QUS, were revealed responding of short-term supplement in this study; however, BMD of the osteoporotic group was still within osteoporosis level. Calcaneal QUS is an alternative technique for assessing the bone. Compared to dual-energy X-ray absorptiometry (DXA), QUS has the advantages of being cheaper, portable, and free of ionizing radiation (Vestergaard et al., 2005). The systematic review on calcaneal QUS, which is potentially useful as a pre-screen tool for assessment of osteoporosis. The calcaneal QUS in screening or stratification algorithm must be based on device-specific cut-offs that are validated in the populations for which they are intended to be used (Thomsen et al., 2015). However, reliable of calcaneal QUS is reliable method, which acceptable used as alternative method for osteoporosis screening due to cost effectiveness and simple access in a rural area (Soontrapa et al., 2008). The review for calcaneal QUS that is able to reflect the bone quality and should be used in the screening of osteoporosis, especially in the developing countries where DXA devices are less accessible to the general population (Chin and Ima-Nirwana, 2013). In our study, T-scores for BMD measurement were estimated the outcome of calcium and vitamin D supplementation in both groups; however, DXA may provide preferable BMD measurement rather than calcaneal QUS. Thus, the evaluation of bone-related biochemical markers including serum vitamin D or $25-(\mathrm{OH}) \mathrm{D}$ was necessary for improving the reliability of this study and providing useful for monitoring bone status before and after supplementation. BTMs are usually represented as bone formation indicators, including procollagen type $1 \mathrm{~N}$-terminal propeptide (P1NP), bone-specific alkaline phosphatase, and bone resorption markers,

Table 1. The different bone mineral density (BMD) and biochemical parameter between before and after calcium-vitamin D supplement in normal elder group $(N=30)^{\mathrm{a}}$.

\begin{tabular}{|c|c|c|c|c|c|c|c|}
\hline \multirow{2}{*}{ Parameter (unit) } & \multirow{2}{*}{ Normal range } & \multirow{2}{*}{ Before supplement } & \multirow{2}{*}{ After supplement } & \multirow{2}{*}{ Paired differences } & \multicolumn{2}{|c|}{$95 \%$ CI } & \multirow{2}{*}{$p$-value } \\
\hline & & & & & Lower & Upper & \\
\hline BMD ( $T$ score $)$ & $>-1.0$ & $-0.80 \pm 0.41$ & $-0.53 \pm 0.48$ & $-0.27 \pm 0.42$ & -0.43 & -0.01 & $0.001 *$ \\
\hline Calcium (mg/dl) & $8.6-10.2$ & $8.94 \pm 0.64$ & $9.03 \pm 0.68$ & $-0.08 \pm 0.26$ & -0.18 & 0.01 & 0.085 \\
\hline Phosphorus (mg/dl) & $2.7-4.5$ & $3.27 \pm 0.83$ & $3.40 \pm 0.89$ & $-0.13 \pm 0.34$ & -0.26 & -0.01 & $0.043^{*}$ \\
\hline Magnesium (mEq/l) & $1.40-2.10$ & $1.92 \pm 0.30$ & $1.99 \pm 0.15$ & $-0.08 \pm 0.25$ & -0.17 & 0.02 & 0.108 \\
\hline $\operatorname{ALP}(\mathrm{U} / 1)$ & $39-105$ & $54.00 \pm 9.19$ & $54.73 \pm 8.97$ & $-0.73 \pm 0.87$ & -1.06 & -0.41 & $<0.0001^{*}$ \\
\hline $25-(\mathrm{OH}) \mathrm{D}(\mathrm{ng} / \mathrm{ml})$ & $\geq 30$ & $40.43 \pm 7.17$ & $41.07 \pm 7.27$ & $-0.63 \pm 1.19$ & -1.08 & -0.19 & $0.007 *$ \\
\hline $\mathrm{OC}(\mathrm{ng} / \mathrm{ml})$ & $11.5-29$ & $16.60 \pm 2.99$ & $16.70 \pm 3.08$ & $-0.10 \pm 0.49$ & -0.28 & 0.08 & 0.264 \\
\hline P1NP (ng/ml) & $15.0-74.0$ & $47.33 \pm 14.34$ & $47.90 \pm 14.47$ & $-0.57 \pm 1.01$ & -0.94 & -0.19 & $0.004 *$ \\
\hline CTX (ng/ml) & $0.0-0.32$ & $0.28 \pm 0.09$ & $0.26 \pm 0.07$ & $0.024 \pm 0.09$ & -0.001 & 0.06 & 0.143 \\
\hline
\end{tabular}

${ }^{\text {a Average age }}=65.4 \pm 9.8$ year old; $*$ Statistically significance at $p<0.05$. 
Table 2. The different bone mineral density (BMD) and biochemical parameter between before and after calcium-vitamin D supplement in osteoporotic elder group $(N=30)^{\mathrm{a}}$.

\begin{tabular}{|c|c|c|c|c|c|c|c|}
\hline \multirow{2}{*}{ Parameter (unit) } & \multirow{2}{*}{ Normal range } & \multirow{2}{*}{ Before supplement } & \multirow{2}{*}{ After supplement } & \multirow{2}{*}{ Paired differences } & \multicolumn{2}{|c|}{$95 \% \mathrm{CI}$} & \multirow{2}{*}{$p$-value } \\
\hline & & & & & Lower & Upper & \\
\hline BMD ( $T$ score $)$ & T score $>-1.0$ & $-2.85 \pm 0.23$ & $-2.53 \pm 0.40$ & $-0.33 \pm 0.43$ & -0.49 & -0.17 & $<0.0001^{*}$ \\
\hline Calcium (mg/dl) & $8.6-10.2 \mathrm{mg} / \mathrm{dl}$ & $6.09 \pm 0.81$ & $6.21 \pm 0.91$ & $-0.12 \pm 0.32$ & -0.24 & -0.001 & $0.048^{*}$ \\
\hline Phosphorus (mg/dl) & $2.7-4.5 \mathrm{mg} / \mathrm{dl}$ & $2.94 \pm 0.70^{\mathrm{a}}$ & $2.94 \pm 0.70^{\mathrm{b}}$ & - & - & - & - \\
\hline $\begin{array}{l}\text { Magnesium } \\
(\mathrm{mEq} / \mathrm{l})\end{array}$ & $1.40-2.10 \mathrm{mEq} / 1$ & $1.36 \pm 0.22$ & $1.37 \pm 0.22$ & $-0.02 \pm 0.01$ & -0.02 & -0.008 & $<0.0001 *$ \\
\hline $\operatorname{ALP}(\mathrm{U} / 1)$ & $39-105 \mathrm{U} / 1$ & $53.63 \pm 9.47$ & $53.97 \pm 10.04$ & $-0.33 \pm 1.45$ & -0.87 & 0.21 & 0.217 \\
\hline 25-(OH) D (ng/ml) & $\geq 30 \mathrm{ng} / \mathrm{ml}$ & $42.07 \pm 7.41$ & $43.13 \pm 7.04$ & $-1.07 \pm 1.44$ & -1.60 & -0.53 & $<0.0001 *$ \\
\hline $\mathrm{OC}(\mathrm{ng} / \mathrm{ml})$ & $11.5-29 \mathrm{ng} / \mathrm{ml}$ & $16.76 \pm 3.45$ & $16.89 \pm 3.64$ & $-0.12 \pm 0.66$ & -0.37 & 0.12 & 0.318 \\
\hline P1NP (ng/ml) & $15.0-74.0 \mathrm{ng} / \mathrm{ml}$ & $45.60 \pm 15.34$ & $45.23 \pm 15.19$ & $0.37 \pm 1.28$ & -0.11 & 0.85 & 0.125 \\
\hline CTX (ng/ml) & $0.0-0.32 \mathrm{ng} / \mathrm{ml}$ & $0.496 \pm 0.165$ & $0.465 \pm 0.160$ & $0.031 \pm 0.023$ & 0.023 & 0.041 & $<0.0001 *$ \\
\hline
\end{tabular}

${ }^{\mathrm{a}}$ Average age $=65.4 \pm 5.4$ year old; ${ }^{\mathrm{b}}$ Before and after values are equal (cannot calculate); $*$ Statistical significance at $p<0.05$.

including C-terminal telopeptide of type-I collagen (CTX) and OC (Lin et al., 2006; Starup-Linde and Vestergaard, 2016; Vasikaran et al., 2011). They may provide information on fracture risk independent of BMD and predict the rapidity of bone loss in untreated patients, which also used to predict the response to treatments. International Osteoporosis Foundation (IOF) and International Federation of Clinical Chemistry and Laboratory Medicine (IFCC) Working Group evaluated BTMs in the prediction of fracture risk and for monitoring treatment; it was recommended that bone formation markers (s-PINP) and bone resorption markers (s-CTX) should be used as reference markers and measured by standardized assays in observational and intervention studies (Sözen et al., 2017; Vasikaran et al., 2011). In our study, vitamin D (25-OH-D), P1NP, ALP, and phosphorus levels of normal BMD group before and after supplement were significantly increased. The finding was implied that short-term supplement was increased the rate of bone formation, which was indicated by elevating of ALP and P1NP along with 25-(OH) D levels. On the other hand, significantly decrement of CTX; and increment of vitamin D, calcium, and magnesium were occurred in the osteoporotic group after supplementation. Hence, the supplement in osteoporosis has increased BMD and may relate to reducing of bone resorption, which was indicated by the reduction of CTX along with elevating of 25-(OH)D calcium and magnesium levels. This study was preliminary done only on selected normal and osteoporosis for clarifying the benefit of BTMs measurements for monitoring BMD status in the short-term supplement. However, osteopenia elders were not included; there was the limitation in this study due to unable to supplement calcium and vitamin D and to monitor BMD and BTMs for all subjects.

This result corresponded to the previous study, which was monitored BMD and bone markers during 1-year supplementation in post-menopausal women and found the decline of CTX level (Slevin et al., 2014).

\section{CONCLUSION}

The finding may provide the useful data on calcaneal QUS combined with bone-related biochemical markers measurement for osteoporosis screening and monitoring for diagnosis and management together rather than diagnosis alone, which was represented in this study that can be prevented and intervene the osteoporosis in normal and osteoporosis by calcium and vitamin
D supplement. In addition, this combined measurement is suitable for mass screening and intervention, especially in the rural area.

\section{ACKNOWLEDGMENTS}

We are grateful to Suan Sunandha Rajabhat University, Bangkok, Thailand for grant support. We would like to sincerely thank all participants from Amphawa district, Samut Songkhram province, Thailand for providing useful data and helping on this research. Special sincere thanks to Samut Songkhram Education Center, Suan Sunandha Rajabhat University for convenience supports, including local public relation and research assistants providing.

\section{CONFLICT OF INTEREST}

There is no conflict of interest related to this research study.

\section{REFERENCES}

Chin KY, Ima-Nirwana S. Calcaneal quantitative ultrasound as a determinant of bone health status: what properties of bone does it reflect? Int J Med Sci, 2013; 10:1778-83.

Consensus conference: osteoporosis. JAMA, 1984; 252:799-802.

Gao LH, Zhu WJ, Liu YJ, Gu JM, Zhang ZL, Wang O, Xing XP, Xu L. Physical performance and life quality in postmenopausal women supplemented with vitamin D: a two-year prospective study. Acta Pharmacol Sin, 2015; 36:1065-73.

IOM (Institute of Medicine). Dietary reference intakes for calcium and vitamin D. National Academies Press, Washington DC, 2011.

Lau EM, Lee JK, Suriwongpaisal P, Saw SM, Das DS, Khir A, Sambrook P. The incidence of hip fracture in four Asian countries: the Asian Osteoporosis Study (AOS). Osteoporos Int, 2001; 12:239-43.

Lin YH, Ho YL, Wang TD, Liu CP, Kao HL, Chao CL, Chien KL, Hung CS, Wu VC, Tsai IJ, Yen RF. The relation of amino-terminal propeptide of type III procollagen and severity of coronary artery disease in patients without myocardial infarction or hibernation. Clin Biochem, 2006; 39:861-6.

Maghbooli Z, Emamgholipour S, Hossein-Nezhad A, Shirzad M, Gorgani-Firuzjaee S. Suitable bone markers assessing bone status in patients with both coronary artery disease and diabetes. J Diabetes Metab Disord, 2016a; 15:35.

Maghbooli Z, Shabani P, Gorgani-Firuzjaee S, Hossein-Nezhad A. The association between bone turnover markers and microvascular complications of type 2 diabetes. J Diabetes Metab Disord, 2016b; 15:51.

Pongchaiyakul C, Songpattanasilp T, Taechakraichana N. Burden of osteoporosis in Thailand. J Med Assoc Thai, 2008; 91:261-7. 
Slevin MM, Allsopp PJ, Magee PJ, Bonham MP, Naughton VR, Strain JJ, Duffy ME, Wallace JM, Mc Sorley EM. Supplementation with calcium and short-chain fructo oligosaccharides affects markers of bone turnover but not bone mineral density in postmenopausal women. J Nutr, 2014; 144:297-304.

Soontrapa S, Soontrapa S, Bunyaratavej N, Rojanasthien S, Kittimanon N, Lektrakul S. Vitamin D status of Thai premenopausal women. J Med Assoc Thai, 2009a; 92:S17-20.

Soontrapa S, Soontrapa S, Chailurkit LO. Hypovitaminosis D in Thailand. J Med Assoc Thai, 2009b; 92:S26-9.

Soontrapa S, Soontrapa S, Chaikitpinyo S. Prevalence of vitamin D insufficiency among elderly males living in rural Khon Kaen Province, Northeast Thailand. J Med Assoc Thai, 2015; 98:S21-5.

Soontrapa S, Soontrapa S, Chaikitpinyo S. The reliability of calcaneal quantitative ultrasound in the measurement of bone mineral density. Srinagarind Med J, 2008; 23:424-9.

Sözen T, Özışık L, Başaran NÇ. An overview and management of osteoporosis. Eur J Rheumatol, 2017; 4:46-56.

Starup-Linde J, Vestergaard P. Biochemical bone turnover markers in diabetes mellitus - a systematic review. Bone, 2016; 82:69-78.

Sudjaroen Y, Thongmuang P. Association of bone-related biochemical markers and risk of prehypertension in osteoporotic elders. Asian J Pharm, 2018; 12:S277-83.

Tai V, Leung W, Grey A, Reid IR, Bolland MJ. Calcium intake and bone mineral density: systematic review and meta-analysis. BMJ, 2015; 351:h4183.

Tang BM, Eslick GD, Nowson C, Smith C, Bensoussan A. Use of calcium or calcium in combination with vitamin $\mathrm{D}$ supplementation to prevent fractures and bone loss in people aged 50 years and older: a metaanalysis. Lancet, 2007; 370:657-66.

Thomsen K, Jepsen DB, Matzen L, Hermann AP, Masud T, Ryg J. Is calcaneal quantitative ultrasound useful as prescreen stratification tool for osteoporosis? Osteoporos Int, 2015; 26:1459-75.

Vasikaran S, Eastell R, Bruyère $\mathrm{O}$, Foldes AJ, Garnero $\mathrm{P}$, Griesmacher A, McClung M, Morris HA, Silverman S, Trenti T, Wahl DA. Markers of bone turnover for the prediction of fracture risk and monitoring of osteoporosis treatment: a need for international reference standard. Osteoporos Int, 2011; 22:391-420.

Vestergaard P, Rejnmark L, Mosekilde L. Osteoporosis is markedly underdiagnosed: a nationwide study from Denmark. Osteoporos Int, 2005; 16:134-41.

Young DS, Bermes EW. Specimen collection and processing: sources of biological variation. In: Burtis CA, Ashwood AR (ed). Tietz textbook of clinical chemistry. 3rd edition, Saunders, Philadelphia, PA, pp. 42-72, 1999.

How to cite this article:

Sudjaroen Y, Thongmuang P. Bone mineral density (BMD) and bone-related biochemical markers after short-term supplementation in normal and osteoporotic elders, the pilot study. J App Pharm Sci, 2018; 8(12): 165-169. 